\title{
Pharmacokinetics/Pharmacodynamics Analysis of the Relationship between the in Vivo Micturition Pressure and Receptor Occupancy of $(R)$-Oxybutynin and Its Metabolite in Rats
}

\author{
Haruhi Mizushima, ${ }^{* a}$ Kazuya Kinoshita, ${ }^{b}$ Koji Abe, ${ }^{c}$ Hitoshi Ishizuka, ${ }^{a}$ and Yasuhiko Yamada ${ }^{d}$ \\ ${ }^{a}$ Clinical Pharmacology and Biostatistics Department, Sankyo Co., Ltd.; ${ }^{b}$ Pharmacodynamics Research Laboratories, \\ Sankyo Co., Ltd.; ${ }^{c}$ Drug Metabolism and Pharmacokinetics Research Laboratories, Sankyo Co., Ltd.; 1-2-58 Hiromachi, \\ Shinagawa-ku, Tokyo 140-8710, Japan: and ${ }^{d}$ Department of Clinical Evaluation of Drug Efficacy, School of Pharmacy, \\ Tokyo University of Pharmacy and Life Science; Hachioji, Tokyo 192-0392, Japan.
}

Received November 28, 2006; accepted February 2, 2007; published online February 8, 2007

To elucidate the relationships between the pharmacokinetics and pharmacological effects of oxybutynin $((R / S)-O X Y)$, the micturition pressure and the plasma concentration profiles of $(R)-O X Y$ and $(R)-N$-desethyloxybutynin $((R)$-DEOB), a pharmacologically active metabolite, after administration by three different routes (i.v., p.o. and transdermal) in rats were measured and analyzed using an inhibitory effect $E_{\max }$ model with their in vitro pharmacological effects. The plasma exposure ratios of $(R)$-DEOB to $(R)$-OXY calculated from the $A U C s$ were somewhat different among the routes administered. $(R)$-OXY and $(R)$-DEOB equally inhibited the acetylcholine-induced contractions in vitro. The micturition pressure, measured using the cystometric method in vivo, exhibited saturation against the dose administered. The inhibitory effect $E_{\max }$ model well described the relationship between the micturition pressure and the receptor occupancy calculated from the plasma concentrations and $\mathrm{pA}_{2}$ values and resulted in an extremely small receptor occupancy $(0.206 \%)$ to exhibit half of the maximum effect. The estimated receptor occupancy profiles suggested a sufficient and long-lasting receptor occupation after transdermal administration of $(R / S)-O X Y$, while the receptor occupancy diminished rapidly after the i.v. and p.o. administration. These data indicate that transdermal administration of $(R / S)$-OXY would be useful to achieve suitable pharmacological effects without excess plasma concentrations.

Key words oxybutynin; $N$-desethyloxybutynin; micturition pressure; receptor occupancy theory; transdermal delivery system

Oxybutynin $((R / S)-\mathrm{OXY})$ is an anticholinergic compound widely used by overactive bladder patients with symptoms of urge urinary incontinence ${ }^{1,2)}$ and several formulations with different pharmacokinetics $(\mathrm{PK})$ profiles of $(R / S)$-OXY are available in the market. $(R / S)$-OXY and $(R / S)$ - $N$-desethyloxybutynin $((R / S)$-DEOB), a pharmacologically active metabolite of $(R / S)$-OXY, inhibit muscarinic acetylcholine receptors in the bladder, especially antagonizing $\mathrm{M}_{2}$ and $\mathrm{M}_{3}$ receptors, which mainly mediate direct contractile response in the blad$\mathrm{der}^{3)}$ and the affinities of both compounds for $\mathrm{M}_{3}$ receptors are higher than those for $\mathrm{M}_{2}$ receptors. $\left.{ }^{4,5}\right)$ Both $(R / S)$-OXY and $(R / S)$-DEOB have an asymmetric carbon, and the $(R)$ enantiomers $((R)$-OXY and $(R)$-DEOB, respectively) have an antimuscarinic effect on the bladder smooth muscle greater than their corresponding $(S)$-enantiomers $((S)$-OXY and $(S)$ DEOB, respectively). ${ }^{6,7)}$ Although several reports have evaluated the relationships between PK exposure and antimuscarinic effects after the administration of $(R / S)-O X Y,{ }^{3,8-13)}$ most of them were not focused on the binding to muscarinic receptors, the competition of $(R / S)$-DEOB with $(R / S)$-OXY for the muscarinic receptor binding sites or the difference of potency between $(R)$ - and $(S)$-enantiomers. In addition, there are few reports elucidating the receptor occupancy to show suitable pharmacological effects of $(R)$-OXY and $(R)$-DEOB.

For compounds which bind internal receptors such as histamine $\mathrm{H}_{1}$ receptor, dopamine receptors, muscarinic receptors, the occupancies of these receptors were extensively examined in order to discover the PK/pharmacodynamic (PD) relationship in the target sites and to determine the appropriate receptor occupancies for their pharmacological effects, including their efficacies and side effects. ${ }^{14-18)}$ These correlations between the receptor occupancies and the $\mathrm{PD} /$ safety parameters would be useful to optimize the dose regimen and formulation. ${ }^{19)}$ In the studies, positron emission tomography $(\mathrm{PET})^{14,15)}$ and the receptor occupancy theory ${ }^{16-18)}$ were used for measuring or predicting the receptor occupancy. PET studies have an advantage in that they can measure the receptor occupancy directly, however, the synthesis of the positron emission substrate and the system of detection are sometimes impediments to conducting a study. On the other hand, the receptor occupancy theory is known as a useful method to predict receptor-mediated pharmacological actions by quantitatively calculating the receptor occupancy of a drug at a target receptor with free plasma concentrations of the drug. This theory has been successfully applied to adrenergic receptors, serotonin 5-HT receptors, dopamine $\mathrm{D}_{2}$ receptors, histamine $\mathrm{H}_{1}$ receptors, muscarinic acetylcholine receptors and so on. ${ }^{16-18)}$

Thus, to understand the PK/PD relationship of $(R / S)$-OXY and $(R / S)$-DEOB, the PK of the enantiomers of $(R / S)$-OXY and $(R / S)$-DEOB after intravenous (i.v.), oral (p.o.) and transdermal administrations and the unbound fractions in plasma were examined in rats. In addition to the $\mathrm{pA}_{2}$ values, calculated from in vitro acetylcholine-induced contractions in rat bladder smooth muscle strips, the micturition pressure after i.v., p.o. and transdermal administrations in vivo were estimated in rat cystometric studies for PD indicators. With these data, the receptor occupancy was calculated from the plasma concentrations using the receptor occupancy theory, and then the relationship between the micturition pressure and the receptor occupancy were evaluated by an inhibitory effect $E_{\max }$ model. 


\section{MATERIALS AND METHODS}

Materials $(R / S)$-OXY $\cdot \mathrm{HCl}$ was provided by Orgamol SA (Evionnaz, Switzerland). $(R)$ - and $(S)$-OXY $\cdot \mathrm{HCl},(R / S)$ $\mathrm{DEOB} \cdot \mathrm{HCl},(R)$ - and $(S)$-DEOB $\cdot \mathrm{HCl}$ were synthesized and supplied by NARD Institute, Ltd. (Hyogo, Japan). Internal standards $\left(\left[{ }^{2} \mathrm{H}_{13}\right]-(R / S)-\mathrm{OXY} \cdot \mathrm{HCl}\right.$ and $\left[{ }^{2} \mathrm{H}_{13}\right]-(R / S)$ $\mathrm{DEOB} \cdot \mathrm{HCl})$ were synthesized and supplied by Chemtech Labo., Inc. (Tokyo, Japan). (R/S)-OXY transdermal delivery systems $\left(13 \mathrm{~cm}^{2}\right.$, containing $12 \mathrm{mg}(R / S)$-OXY or without $(R / S)$-OXY as placebo) were obtained from Watson Pharmaceuticals, Inc (Corona, CA, U.S.A.).

Animals Male CD(SD)IGS rats (8-9 weeks) were purchased from Charles River Laboratories Japan, Inc. (Kanagawa, Japan). The rats were housed with free access to food and water. The rats for the PK study were fasted for between 16 and $19 \mathrm{~h}$ before administration and for $8 \mathrm{~h}$ after administration. All the rats were maintained under a $12 \mathrm{~h}$ cycle of light/dark artificial lighting at $21-25^{\circ} \mathrm{C}$.

Pharmacokinetic Study after Single i.v., p.o. and Transdermal Administration to Rats The rats were anesthetized with diethyl ether and $(R / S)$-OXY, $(R)$-OXY and $(R / S)$-DEOB $(0.5 \mathrm{mg} / \mathrm{kg}$ as a free base) were injected intravenously via the femoral vein. $(R / S)$-OXY $(50 \mathrm{mg} / \mathrm{kg}$ as a free base) was administered to the rats orally. All the compounds were dissolved in saline. $(R / S)$-OXY transdermal delivery systems (12, 24 and $48 \mathrm{mg} /$ body as a free base) were applied for $48 \mathrm{~h}$ on the shaved backs of the rats after anesthetization with diethyl ether. Blood samples with heparin were collected via the tail vein after administration and centrifuged immediately. The obtained plasma samples were stored below $-20^{\circ} \mathrm{C}$ until the analysis.

Quantification of the Enantiomers of OXY and DEOB in Rat Plasma Plasma $(25 \mu \mathrm{l})$ was mixed with $150 \mu \mathrm{l}$ of methanol containing internal standards. To the mixed plasma aliquot, $500 \mu \mathrm{l}$ of carbonate buffer $\left(0.5 \mathrm{~mol} / 1\right.$ of $\mathrm{Na}_{2} \mathrm{CO}_{3}$ and $0.5 \mathrm{~mol} / 1$ of $\left.\mathrm{NaHCO}_{3}, \mathrm{pH} 9.5\right)$ and $7 \mathrm{ml}$ of $n$-hexane were added. After being shaken for $10 \mathrm{~min}$, the mixture was centrifuged, and the organic phase was removed and evaporated to dryness under a nitrogen stream. The residue was reconstituted with $100 \mu \mathrm{l}$ of $10 \mathrm{mmol} / \mathrm{l}$ ammonium formate solution (pH 4.0) and acetonitrile $(95: 5, \mathrm{v} / \mathrm{v})$. A ChromTech ChiralAGP $(2.0 \mathrm{~mm}$ i.d. $\times 150 \mathrm{~mm}, 5 \mu \mathrm{m})$ (Regis Technologies, Inc. Morton Grove, IL, U.S.A.) and an API 4000 MS/MS (MDS Sciex, Ontario, Canada) connected to a Shimadzu 10A (Shimadzu Corporation, Kyoto, Japan) were used for the simultaneous assay of the enantiomer concentrations of OXY and DEOB by LC-MS/MS. A mixture of $10 \mathrm{mmol} / 1$ ammonium formate solution $(\mathrm{pH} 4.0)$ and acetonitrile $(90: 10, \mathrm{v} / \mathrm{v})$ was used as the mobile phase at a flow rate of $0.2 \mathrm{ml} / \mathrm{min}$. The lower limit of quantification was $2 \mathrm{ng} / \mathrm{ml}$ for each compound.

Unbound Fractions of the Enantiomers of OXY and DEOB in Rat Plasma The plasma unbound fractions of each enantiomer of OXY and DEOB were determined using the high-performance frontal analysis (HPFA) method described previously ${ }^{20,21)}$ with slight modifications. To $1980 \mu \mathrm{l}$ rat plasma $(n=3), 20 \mu \mathrm{l}$ of methanol containing the test substance (final conc.: $200 \mathrm{ng} / \mathrm{ml}$ for $(R)$ - and $(S)$-OXY, $400 \mathrm{ng} / \mathrm{ml}$ for $(R)$ - and $(S)$-DEOB) was added. After $1.5 \mathrm{ml}$ of the sample was directly injected into the HPFA column, the unbound drug that was eluted as a zonal peak with a plateau region was determined at $210 \mathrm{~nm}$. The HPFA column and the analytical column were kept at $37^{\circ} \mathrm{C}$ in a column oven at all times during this procedure. A mixture of methanol and water $(50: 50, \mathrm{v} / \mathrm{v}$, for OXY, $48: 52, \mathrm{v} / \mathrm{v}$, for DEOB) containing $10 \mathrm{~mm}$ ammonium formate was used as the mobile phase of the analytical column at a flow rate of $1 \mathrm{ml} / \mathrm{min}$.

Acetylcholine-Induced Contraction in Bladder Smooth Muscle Strip Urinary bladder strips were isolated from the rats. The abdomen was opened, and the urinary bladder was removed. The urinary bladder was then cut along the circular muscle axis. Circular strips were made and suspended along their circular axis in a tissue bath filled with Krebs solution. The muscle strips were maintained at $37^{\circ} \mathrm{C}$ in an atmosphere of $95 \% \mathrm{O}_{2}+5 \% \mathrm{CO}_{2}$. The response of the strips was measured isometrically under a resting tension of $10 \mathrm{mN}$ using a multipen recorder (U-228, PANTOS, Japan).

Concentration-response curves for acetylcholine were obtained by increasing the concentration in a stepwise manner after the response to the previous concentration had reached a plateau. After cumulative concentration-response curves were generated in the absence of drugs, the strips were washed several times with Krebs solution and allowed to relax to baseline. The strips were then incubated with drugs for $5 \mathrm{~min}$ and the concentration-response curves for acetylcholine were obtained in the presence of increasing concentrations of each drug.

Surgical Procedure for Cystometry Experiments The rats were anesthetized with $50 \mathrm{mg} / \mathrm{kg}$ intraperitoneal pentobarbital sodium and placed in a supine position. The abdomen was opened by midline laparotomy, and the urinary bladder was gently exteriorized. A polyethylene catheter was implanted into the bladder through a small incision at the apex of the bladder dome. The catheter was tunneled subcutaneously and secured with a silk suture on the back of the animal. In the case of the i.v. administration of drugs, the jugular vein was also cannulated for drug administration. The cytometry experiments were carried out over $7 \mathrm{~d}$ after the catheter implantation.

Measurement of Micturition Pressure after Single i.v., p.o. and Transdermal Administration to Rats On the day of the experiment, the catheters which were implanted in the bladders of the rats were connected to a pressure transducer (P23XL-1, Japan Becton Deckinson, Japan, or TP-300T, Nihon Kohden Corporation, Japan) and to an infusion pump (SP-80RS, Nipro Corporation, Japan, or SP-02, JMS Co., Ltd., Tokyo, Japan). Saline was infused into the bladders continuously at a rate of $6 \mathrm{ml} / \mathrm{h}$. The intravesical pressure was recorded continuously with a MacLab system (ADInstruments, Colorado Springs, CO, U.S.A.). The micturition pressure was evaluated from the recorded cystometrograms. The micturition pressure was measured for $30 \mathrm{~min}$ before and after administration of the drugs for the i.v. administration of vehicle, $(R / S)$-OXY, $(R)$-OXY and $(R / S)$-DEOB $(0.2,0.4$ and $0.8 \mathrm{mg} / \mathrm{kg}$ each as a free base). In the oral administration of the vehicle and $(R / S)$-OXY $(3.75,7.5,15$ and $30 \mathrm{mg} / \mathrm{kg}$ as a free base), the micturition pressure was measured for $30 \mathrm{~min}$ before and at $1 \mathrm{~h}$ after administration. After administration of the placebo and $(R / S)$-OXY transdermal delivery system $(6$, 12 and $24 \mathrm{mg} /$ body as a free base) on the shaved backs of the rats, the micturition pressure was measured for $30 \mathrm{~min}$ before application and at $24 \mathrm{~h}$ post-application. For the $72 \mathrm{~h}$ applica- 
tion of the $(R / S)$-OXY transdermal delivery system, the micturition pressure was measured before and at 3, 6, 24, 48 and $72 \mathrm{~h}$ after administration of the placebo or the $(R / S)$-OXY transdermal delivery system $(6,12$ and $24 \mathrm{mg} /$ body as a free base).

PK/PD Analysis between Micturition Pressure and Receptor Occupancy The receptor occupancies $(\Phi)$ for $(R)$ OXY and $(R)$-DEOB were calculated by the following Eq. 1:

$$
\begin{aligned}
\Phi= & {\left[\frac{C_{\mathrm{f}_{-} \mathrm{OXY}}}{K_{\mathrm{D} \_\mathrm{OXY}} \times\left\{1+\left(C_{\mathrm{f} \_\mathrm{DEOB}} / K_{\mathrm{D} \_\mathrm{DEOB}}\right)\right\}+C_{\mathrm{f} \_\mathrm{OXY}}}\right.} \\
& \left.+\frac{C_{\mathrm{f} \_\mathrm{DEOB}}}{K_{\text {D_DEOB }} \times\left\{1+\left(C_{\mathrm{f} \_\mathrm{OXY}} / K_{\text {D_OXY }}\right)\right\}+C_{\mathrm{f} \_\mathrm{DEOB}}}\right] \times 100
\end{aligned}
$$

where $C_{\text {f_OXY }}$ and $C_{\text {f_DEOB }}$ are the plasma unbound concentrations for $(R)-\mathrm{OXY}$ and $(R)$-DEOB, respectively. $K_{\mathrm{D} \_\mathrm{OXY}}$ and $K_{\mathrm{D} \_\mathrm{DEOB}}$ are the receptor dissociation constants, estimated from the $\mathrm{pA}_{2}$ values $\left(K_{\mathrm{D}}=10^{-\mathrm{pA}_{2}}\right)$ for $(R)-\mathrm{OXY}$ and $(R)$ DEOB, respectively. $C_{\mathrm{f} \text { _OXY }}$ and $C_{\mathrm{f} \text { DEOB }}$ were calculated from the unbound fractions and the mean plasma concentrations. For the inhibitory effect $E_{\max }$ model, the receptor occupancies at $30 \mathrm{~min}$ and at $60 \mathrm{~min}$ were used for i.v. and p.o. administration, respectively. For the transdermal administrations, the receptor occupancy at the time corresponding to the micturition pressure measurement was used. The receptor occupancies at $3 \mathrm{~h}$ were estimated from the average concentrations calculated from the concentrations at 2 and $4 \mathrm{~h}$ and those at $6 \mathrm{~h}$ were estimated from the average concentrations calculated from the concentrations at 4 and $8 \mathrm{~h}$. The micturition pressure at $72 \mathrm{~h}$ was not used for this analysis due to the unavailability of the concentrations at $72 \mathrm{~h}$. The mean plasma concentrations were adjusted appropriately with the dosages.

The relationship of the micturition pressure to the calculated receptor occupancy was analyzed by the inhibitory effect $E_{\max }$ model expressed by the following Eq. 2:

$$
E=E_{0}-\frac{E_{\max } \times \Phi}{E \Phi_{50}+\Phi}
$$

where $E$ is the observed mean micturition pressure, $E_{0}$ is the mean baseline micturition pressure, $E_{\max }$ is the maximum inhibition of micturition pressure, $E \Phi_{50}$ is the receptor occupancy at $50 \%$ of $E_{\max }$.

Parameter Calculation and Statistical Analysis The non-compartmental PK parameters after i.v., p.o. and transdermal administration of $(R / S)$-OXY were calculated as follows. The area under the plasma concentration-time curve $(A U C)$ was calculated for each compound by linear trapezoidal rule. The maximum concentration $\left(C_{\max }\right)$ and the time to reach the maximum observed plasma concentration $\left(t_{\max }\right)$ were reported as the observed values. The elimination halflife $\left(t_{1 / 2}\right)$ was calculated for each compound as $\ln 2 / k_{\mathrm{el}}$, where $k_{\mathrm{el}}$ is a first order rate constant associated with the log-linear portion of the curve. The unbound fraction was calculated by dividing the unbound concentration by the total plasma concentration in each test concentration.

To assess the potency of the anti-muscarinic action, the ratio of the $\mathrm{EC}_{50}$ values (CR) for the acetylcholine-induced contractions in the presence and in the absence of drugs was obtained. Schild plots were obtained by plotting the $\log (\mathrm{CR}-1)$ against the log molar concentration of the drug, and the $\mathrm{pA}_{2}$ values were derived from the Schild plots ac- cording to the method described by Arunlakshana and Schild. ${ }^{22)}$ The relative values of the micturition pressure after administration were calculated against the value of the micturition pressure before administration.

$E \Phi_{90}$, the receptor occupancy at $90 \%$ of $E_{\max }$, was calculated from the estimated parameters obtained from the $\mathrm{PK} / \mathrm{PD}$ analysis.

For the micturition pressure, each drug-treated group was compared with the placebo or the vehicle-treated group at each measurement point by a Dunnett test. A $p$ value less than 0.05 was considered to be statistically significant. This test was conducted with SAS System Release 8.2 (SAS Institute Inc.)

Calculation of the PK parameters and the inhibitory effect $E_{\max }$ model analysis was done with WinNonlin ${ }^{\circledR}$ Professional Version 4.1 and 5.0.1 (Pharsight Corp. Mountain View, CA, U.S.A.). All the other calculations were performed using SAS System Release 8.2, or Microsoft ${ }^{\circledR}$ Excel 97 or later versions (Microsoft Corporation, Redmond, WA, U.S.A.).

\section{RESULTS}

Pharmacokinetics after i.v., p.o. and Transdermal Administration to Male Rats The plasma concentrations of the OXY and DEOB enantiomers after the single administrations of $(R / S)$-OXY, $(R)$-OXY and $(R / S)$-DEOB and the PK parameters are summarized in Figs. $1-3$ and Table $1 .(R)$ and $(S)$-DEOB were not detected after the i.v. administrations of $(R / S)-\mathrm{OXY}$ and $(R)-\mathrm{OXY}$. The systemic exposure of $(R)$ DEOB was the highest among the enantiomers, and was remarkably higher than that of $(R)$-OXY after the p.o. administration of $(R / S)$-OXY $(50 \mathrm{mg} / \mathrm{kg})$ (Fig. 2). The $A U C_{0-24 \mathrm{~h}}$ and $C_{\max }$ of $(R)$-DEOB were approximately four and five-fold higher than those of $(R)$-OXY after the single p.o. administration (Table 1). With regard to the transdermal administrations, the plasma concentrations of $(R)$ - and $(S)$-OXY were remarkably higher than those of $(R)$ - and $(S)$-DEOB. The dose linearities of $(R)$ - and $(S)$-OXY were observed between 12 and $48 \mathrm{mg} /$ body (data not shown). After the single transdermal administrations, the $A U C_{0-72 \mathrm{~h}}$ and $C_{\max }$ of $(R)-\mathrm{OXY}$ were over 10 -fold greater than those of $(R)$-DEOB at all doses. $t_{\max }$ after the single transdermal administration was longer than those after the p.o. administration, and there were no remarkable differences in the $t_{1 / 2}$ values observed among the three routes (Table 1).

In Vitro Unbound Fractions of the Enantiomers in Rat Plasma The unbound fractions at $200 \mathrm{ng} / \mathrm{ml}$ nominal in rat plasma of $(R)$ - and $(S)$-OXY were $1.92 \pm 0.14$ and $1.95 \pm 0.12$ $(\%$, mean \pm S.E., $n=3)$, respectively. Those at $400 \mathrm{ng} / \mathrm{ml}$ nominal of $(R)$ - and $(S)$-DEOB were $8.34 \pm 0.30$ and $7.70 \pm$ 0.15 , respectively $(\%, n=3)$.

In Vitro Inhibition on Acetylcholine-Induced Smooth Muscle Contraction in Isolated Male Rat Urinary Bladder The Schild plots of $(R)-\mathrm{OXY}$ and $(R)$-DEOB are shown in Fig. 4. The $\mathrm{pA}_{2}$ values of $(R)$-OXY and $(R)$-DEOB were 7.27 [6.98 - 7.98] and 7.42 [6.90 - 17.19] (estimated value [95\% confidence interval]), respectively. Those of $(S)$ OXY and $(S)$-DEOB couldn't be calculated due to insufficient inhibition.

Micturition Pressure after i.v., p.o. and Transdermal Administration to Male Rats After the i.v. administration, 

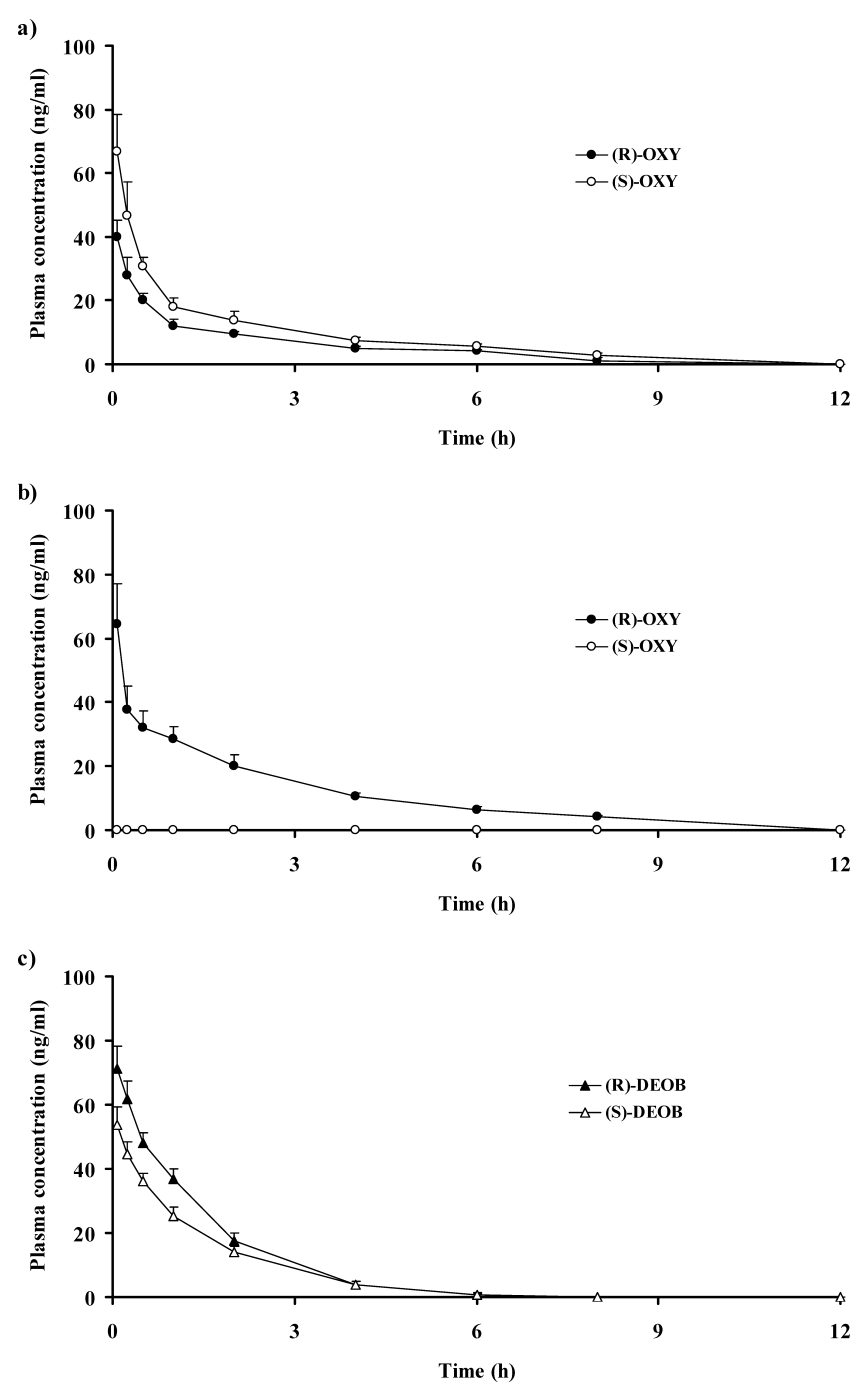

Fig. 1. Mean Plasma Concentrations of OXY and DEOB Enantiomers after a Single i.v. Administrations of $(R / S)$-OXY (a), $(R)$-OXY (b) and $(R / S)$ DEOB (c) to Male Rats at a Dose of $0.5 \mathrm{mg} / \mathrm{kg}($ Mean + S.E., $n=3-4)$

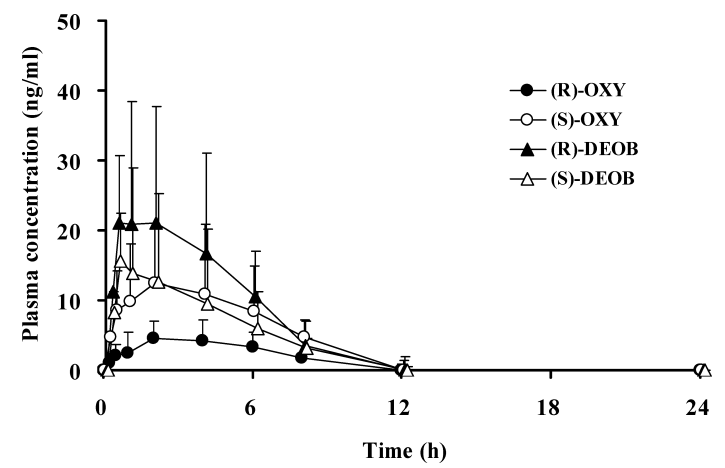

Fig. 2. Mean Plasma Concentrations of OXY and DEOB Enantiomers after a Single p.o. Administration of $(R / S)$-OXY to Male Rats at a Dose of $50 \mathrm{mg} / \mathrm{kg}($ Mean + S.E., $n=4)$

significant reductions of the micturition pressure were observed at doses over $0.4 \mathrm{mg} / \mathrm{kg}$ for each administrated compound. The micturition pressures were significantly reduced at $1 \mathrm{~h}$ after the administration of $(R / S)$-OXY at doses of 7.5 and $15 \mathrm{mg} / \mathrm{kg}$ p.o. Similarly, the micturition pressures were significantly reduced at $24 \mathrm{~h}$ after the transdermal applica-
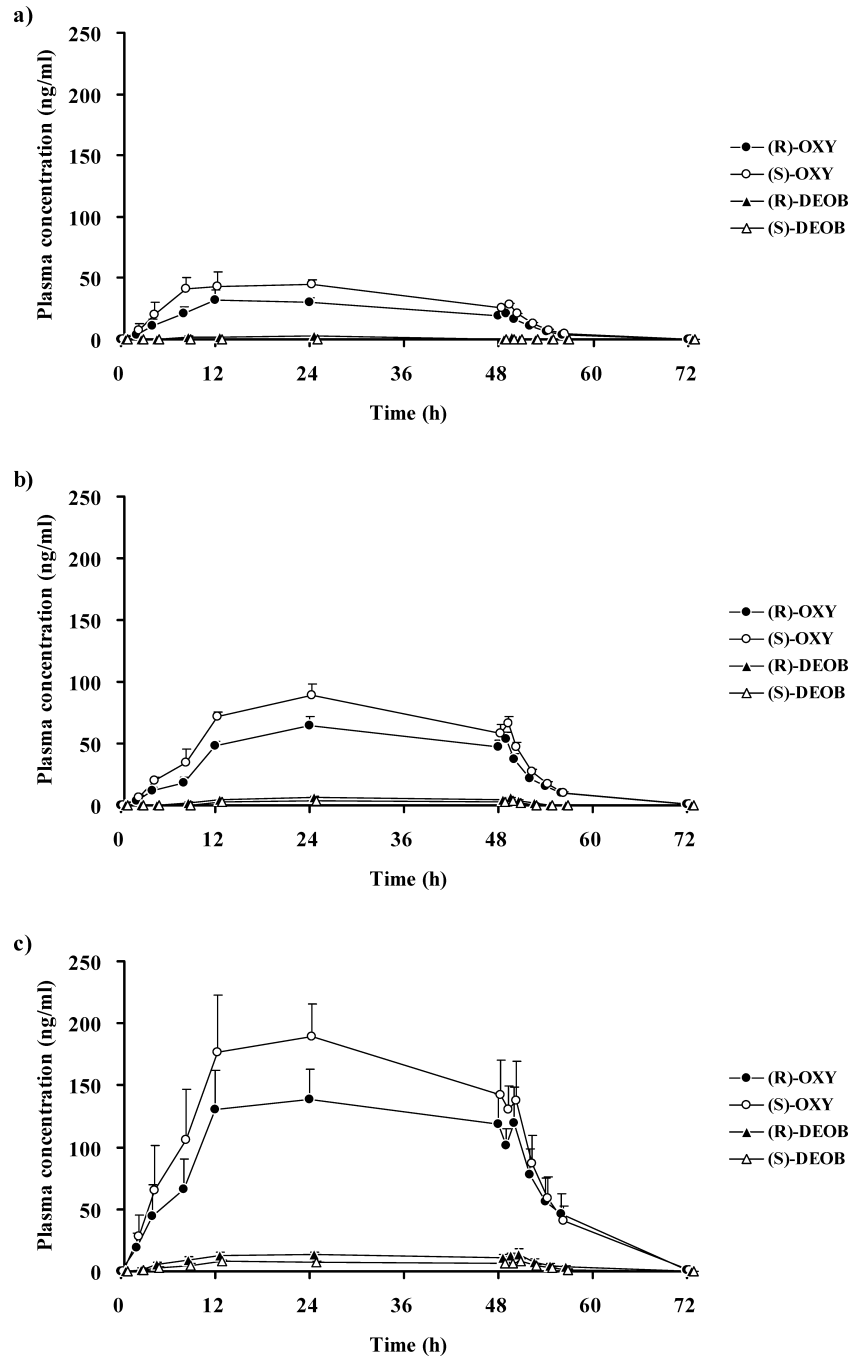

Fig. 3. Mean Plasma Concentrations of OXY and DEOB Enantiomers after a Single Transdermal Administration of $(R / S)$-OXY to Male Rats for $48 \mathrm{~h}$ at Doses of 12 (a), 24 (b) and 48 (c) mg/body (Mean+S.E., $n=3$ )

The transdermal delivery system was removed at $48 \mathrm{~h}$.

tions of (R/S)-OXY at doses of 6 and $24 \mathrm{mg} /$ body (Fig. 5). The micturition pressures during the transdermal application of $(R / S)$-OXY were nearly constant at each point for all doses (Fig. 6). The micturition pressures exhibited saturations against dose administered.

Inhibitory Effect $E_{\max }$ Model Analysis between the Receptor Occupancy and the Micturition Pressure The relationship between the mean micturition pressure and the receptor occupancy, calculated with the mean plasma concentrations of $(R)$-OXY and $(R)$-DEOB, was well described by the inhibitory effect $E_{\max }$ model via the three administration routes simultaneously (Fig. 7). $E_{0}$ was $101 \pm 3.38 \%$ (estimated value \pm computer calculated S.E.), $E_{\max }$ was $29.3 \pm$ $4.67 \%$ and $E \Phi_{50}$ was $0.206 \pm 0.267 \%$ (Table 2) and $E \Phi_{90}$ was calculated as $1.85 \%$.

Estimation of Time Profiles of Receptor Occupancy after Single i.v., p.o. and Transdermal Administration of $(\boldsymbol{R} / \boldsymbol{S})$-OXY The receptor occupancies after the i.v. and p.o. administrations increased transiently, and then returned to zero by $8 \mathrm{~h}$ after the i.v. administration and by $12 \mathrm{~h}$ after the p.o. administration. The decrease of the receptor occupancy 
after i.v. administration was more rapid than that after p.o. administration. The receptor occupancy after the p.o. administration exceeded $E \Phi_{90}$, while that after i.v. administration did not (Fig. 8a). On the other hand, the receptor occupancies increased gradually and the maximum occupancies were observed by $24 \mathrm{~h}$ after the transdermal applications of $(R / S)$ OXY at doses of 12,24 and $48 \mathrm{mg} /$ body, after which they were stable during the applications. The receptor occupancies decreased and returned to zero by $24 \mathrm{~h}$ after removals. The maximum receptor occupancy at dose of $12 \mathrm{mg} /$ body was equivalent to that after $0.5 \mathrm{mg} / \mathrm{kg}$ i.v. administration. That at dose of $48 \mathrm{mg} /$ body was higher than that after $50 \mathrm{mg} / \mathrm{kg}$ p.o. administration. Stable and higher receptor occupancies than $E \Phi_{90}$ were observed during the applications of the transdermal delivery systems at the three doses examined (Fig. 8b).

\section{DISCUSSION}

The quantitative evaluation of the PK/PD relationship of a medical compound, including its active metabolite, is very helpful for predicting the pharmacological effect of the compound. Regarding $(R / S)$-OXY, it was reconfirmed that $(R)$ OXY and $(R)$-DEOB, and not their $(S)$-enantiomers, have comparative binding activity to inhibit muscarinic acetylcholine receptors in the bladder in our in vitro study in rats. The pharmacokinetics of $(R)$-OXY and $(R)$-DEOB in rats was different among the administration routes tested, that is, $(R)$-DEOB was not detected or was quite low in plasma after the i.v. and transdermal administrations, while $(R)$-DEOB was four to five-fold higher than (R)-OXY after the p.o. administration. Taking these findings into consideration, in order to understand the pharmacological effects of $(R / S)$ OXY, it is necessary to analyze the relationship between the micturition pressure and the PK of $(R)$-OXY and $(R)$-DEOB simultaneously. Thus, we analyzed the relationship between the micturition pressure and the muscarinic receptor occupancy of $(R)$-OXY and $(R)$-DEOB using the receptor occupancy theory and an inhibitory effect $E_{\max }$ model in rats.

An extremely small receptor occupancy was necessary to achieve half of the maximum effect of this drug in rats. The relatively low receptor occupancy of muscarinic receptors has been reported for several anticholinergic agents used for treating overactive bladders (submitted for publication). It has also been reported that an elderly woman who had paroxetine-induced dry mouth recovered from the dryness by replacing paroxetine hydrochloride of $10 \mathrm{mg} / \mathrm{d}$ with fluvoxamine maleate of $50 \mathrm{mg} / \mathrm{d}$. In this case, the calculated receptor occupancy for fluvoxamine maleate was $0.020 \%$, while that for paroxetine hydrochloride was $0.22 \%,{ }^{23)}$ indicating that the antagonists for the muscarinic receptor might be pharmacologically effective even with low receptor occupancies.

The maximum inhibition of micturition pressure was saturated at $29.3 \%$, suggesting that higher efficacy would not be expected even at higher doses in rats. This result corresponded with the saturation of the micturition pressure against the dose administered. The inhibitory effect $E_{\max }$ model analysis described the relationship between the micturition pressure and the receptor occupancy adequately apart from the route of administration in rats. The estimated time profiles of the receptor occupancy indicated continuous receptor occupation during the transdermal application, while 
a)

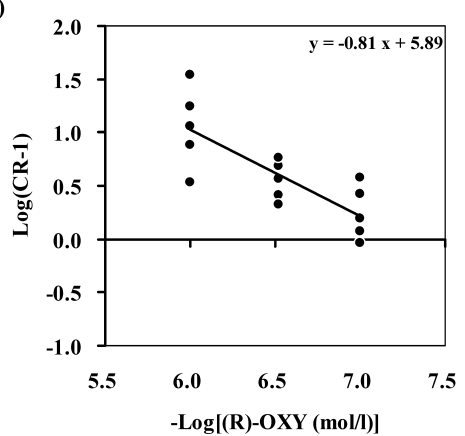

b)

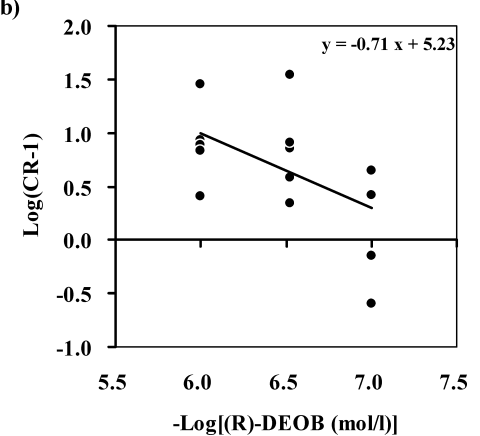

Fig. 4. Schild Plots of $(R)$-OXY (a) and $(R)$-DEOB (b) in Isolated Rat Urinary Bladder Strips

The lines indicate the results of linear regression analysis. $\mathrm{CR}$ is the ratio of the $\mathrm{EC}_{50}$ values for the acetylcholine-induced contractions in the presence and in the absence of drugs.

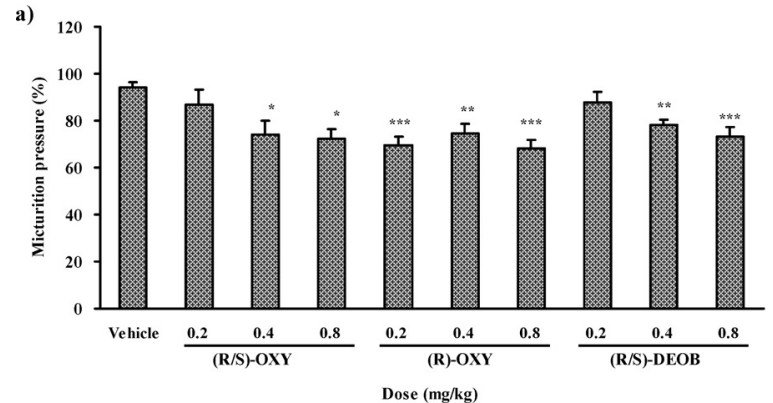

b)

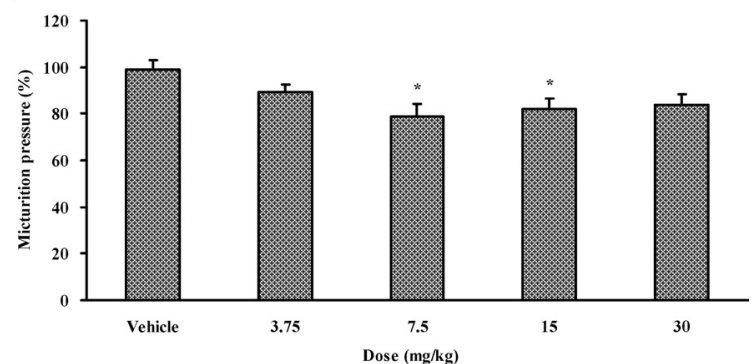

c)

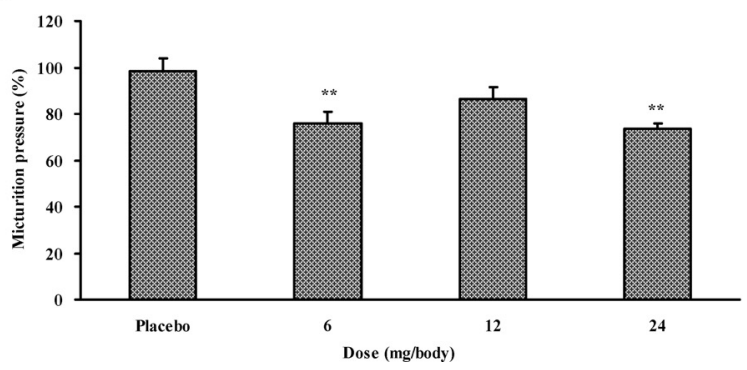

Fig. 5. Mean Micturition Pressure after Single i.v. Administration of $(R / S)$-OXY, $(R)$-OXY and $(R / S)$-DEOB (a), a Single p.o. Administration of $(R / S)$-OXY (b) and a Single Transdermal Administration of $(R / S)$-OXY (c)

The micturition pressures were measured at $30 \mathrm{~min}, 1 \mathrm{~h}$ and $24 \mathrm{~h}$ after the administration, for i.v., p.o. and transdermal administration, respectively. The doses were $0.2,0.4$ and $0.8 \mathrm{mg} / \mathrm{kg}$ for the i.v. administration, $3.75,7.5,15$ and $30 \mathrm{mg} / \mathrm{kg}$ for the p.o. administration and 6, 12 and $24 \mathrm{mg} /$ body for the transdermal administration (mean \pm S.E. $n=8$ (i.v.) or $n=12$ (p.o. and transdermal). $* p<0.05$, $* * p<0.01$ and $* * * p<0.001$, compared with the placebo or vehicle-treated group by a Dunnett test.

the time to reach the maximum receptor occupancy after the transdermal administration was slower than those after the i.v. and p.o. administrations. It was suggested that transdermal administration was sufficient in rats, even at $12 \mathrm{mg} / \mathrm{body}$, because the receptor occupancies during the $12 \mathrm{mg} / \mathrm{body}$ transdermal administrations exceeded $E \Phi_{90}$. Considering

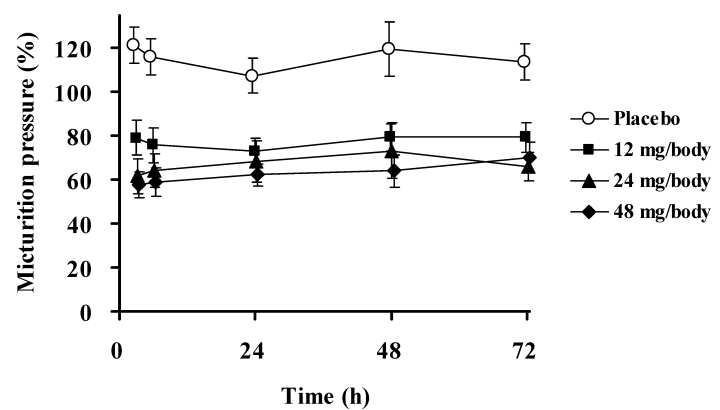

Fig. 6. Mean Micturition Pressures after a Single Transdermal Administration of $(R / S)$-OXY to Male Rats for $72 \mathrm{~h}$ at Doses of 12,24 and $48 \mathrm{mg} /$ body (Mean \pm S.E., $n=15$ (12 and $24 \mathrm{mg} /$ body) or $n=16$ (Placebo and $48 \mathrm{mg} /$ body))

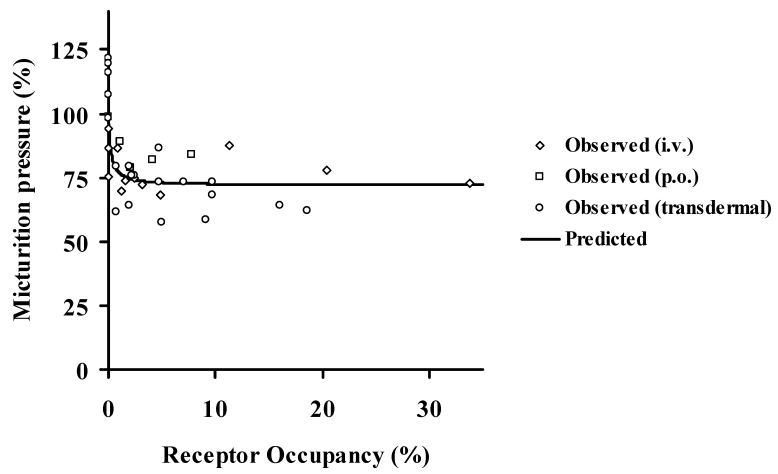

Fig. 7. Relationship between the Receptor Occupancy of Acetylcholine Receptor and the Micturition Pressure in Male Rats

The predicted line was generated based on the inhibitory effect $E_{\max }$ model analysis.

Table 2. Estimated Parameters of the Inhibitory Effect $E_{\max }$ Model Analysis of the Relationship between the Mean Micturition Pressure and the Receptor Occupancy in Male Rats

\begin{tabular}{lcl}
\hline \hline & Estimated parameters & S.E. \\
\hline$E_{0}(\%)$ & 101 & 3.38 \\
$E_{\max }(\%)$ & 29.3 & 4.67 \\
$E \Phi_{50}(\%)$ & 0.206 & 0.267 \\
\hline
\end{tabular}

these facts, it may be reasonable to administer $(R / S)$-OXY by transdermal formulation in order to avoid excess plasma concentrations in humans. A transient increase in receptor occu- 

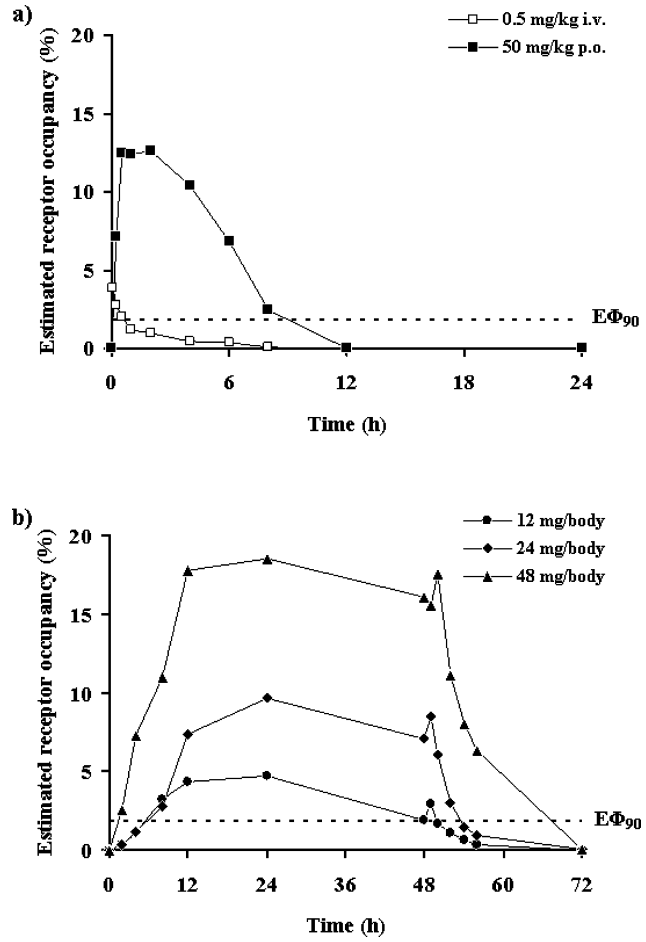

Fig. 8. Simulated Receptor Occupancies after Single i.v. and p.o. Administrations (a) and Transdermal Application of $(R / S)-\mathrm{OXY}$

The doses were $0.5 \mathrm{mg} / \mathrm{kg}$ for the i.v. administration, $50 \mathrm{mg} / \mathrm{kg}$ for the p.o. administration, and 12, 24 and $48 \mathrm{mg} /$ body for the transdermal administration. The receptor occupancy was calculated with the plasma concentrations of $(R)$-OXY and $(R)$-DEOB.

pancy was observed $1 \mathrm{~h}$ after the removal, accompanying that in the plasma concentration. This was also observed in human plasma after the system removal. ${ }^{24)}$ There have been no data available for this phenomenon, however, stimulation as a result of the removal could be one of the causes of this increase. However, it is not considered that the increase in receptor occupancy influences the effect in the bladder because the increase is relatively small.

It is generally accepted that the receptor occupancy theory will be applicable in cases where the concentrations in the target organs are assumed to be in equilibrium with the plasma concentration. ${ }^{17,18)}$ Although we didn't clearly demonstrate rapid equilibrium in our experiments, our results show that the relationships between the receptor occupancy and the micturition pressure after the i.v. and p.o. administrations were similar to that solely after the transdermal administration. Additionally, it was reported that the micturition pressure was suppressed significantly at 15 to $60 \mathrm{~min}$ after i.v. $(R / S)$-OXY administration and 1 to $5 \mathrm{~h}$ after p.o. administration in rat. ${ }^{25)}$ These would indicate that the concentrations of $(R)$-OXY and $(R)$-DEOB in the bladder might be rapidly equilibrated with plasma concentration after administration regardless of the administration route.

The results of the analysis using the linear inhibitory model, which did not improve the fitting between the effect and the receptor occupancy, compared to the inhibitory effect $E_{\max }$ model (data not shown), indicated that the non-linear relation between the receptor occupancy of the muscarinic receptors and the micturition pressure as well as the relation between the receptor occupancy and the plasma concentrations of $(R)-\mathrm{OXY}$ and $(R)$-DEOB. These results indicate a non-linear process between the receptor binding and the inhibition of contractions in the bladder smooth muscle. This would be reasonable because there are a number of steps to contraction, that is, $\mathrm{M}_{2}$ and $\mathrm{M}_{3}$ receptors interact with $\mathrm{G}$ proteins, which leads to $\mathrm{Ca}^{2+}$ mobilization and contraction. ${ }^{26)}$

Incidentally, due to the lower limit of quantification, the unbound fractions used for PK/PD analysis were acquired at higher substance concentrations than those in vivo. Therefore, these results may not reflect the relationship between the receptor occupancy and the micturition pressure accurately. However, the saturation of the micturition pressure and the very low $E \Phi_{50}$ might be authentic, because the unbound fractions were nearly equivalent to those at higher substance concentrations (data not shown).

Extrapolation of the pharmacological effects from nonclinical to clinical based on modeling seems to be highly useful in providing useful information for clinical trials. The binding affinity of histamine $\mathrm{H}_{3}$ receptor agonists correlated well among humans, dogs, rats and guinea pigs, while that of histamine $\mathrm{H}_{3}$ receptor antagonists showed lower correlation. ${ }^{27)}$ Though it has been reported that human $K_{\mathrm{I}}$ values for muscarinic receptors are highly correlated with those of animals (submitted for publication), it might be difficult to precisely predict the suitable dosage regimens and formulation of $(R / S)$-OXY to achieve stable and long-lasting efficacy for humans, because we have little information for promising receptor occupancy to exhibit the important clinical effects in human patients.

In conclusion, the inhibitory effect $E_{\max }$ model well described the relationship between the micturition pressure and the receptor occupancy calculated from the plasma concentrations, regardless of the administration route used in rats. The estimated receptor occupancy profiles suggested sufficient and long-lasting receptor occupation after transdermal administration of $(R / S)$-OXY. These results may be helpful in understanding the pharmacokinetics and pharmacodynamics relationships after the dosing of $(R / S)$-OXY related compounds in humans.

\section{REFERENCES}

1) Appell R. A., Sand P., Dmochowski R., Anderson R., Zinner N., Lama D., Roach M., Miklos J., Saltzstein D., Boone T., Staskin D. R., Albrecht D., Mayo Clin. Proc., 76, 358-363 (2001).

2) Diokno A. C., Appell R. A., Sand P. K., Dmochowski R. R., Gburek B. M., Klimberg I. W., Kell S. H., Mayo Clin. Proc., 78, 687-695 (2003).

3) Hegde S. S., Br. J. Pharmacol., 147, S80-S87 (2006).

4) Nivebrant L., Andersson K. E., Gillberg P. G., Stahl M., Sparf B., Eur. J. Pharmacol., 327, 195-207 (1997).

5) Maruyama S., Oki T., Otsuka A., Shinobu H., Ozono S., Kageyama S., Mikami Y., Araki I., Takeda M., Masuyama K., Yamada S., J. Urol., 175, 365-369 (2006).

6) Noronha-Blob L., Kachur J. F., J. Pharmacol. Exp. Ther., 256, $562-$ 567 (1990).

7) Smith E. R., Wright S. E., Aberg G., Fang Y., McCullough J. R., Arzneim-Forsch/Drug Res., 48, 1012 -1018 (1998).

8) Sathyan G., Chancellor M. B., Gupta S. K., Br. J. Clin. Pharmacol., 52, 409-417 (2001)

9) Appell R. A., Chancellor M. B., Zobrist R. H., Thomas H., Sanders S. W., Mayo Clin. Proc., 78, 696-702 (2003).

10) Lehtoranta K., Tainio H. Lukkari-Lax E., Hakonen T., Tammela T. L., Scand. J. Urol. Nephrol., 36, 18-24 (2002).

11) Di Stasi S. M., Giannantoni A., Navarra P., Capelli G., Storti L., Porena M., Stephen R. L., J. Urol., 166, 2232-2236 (2001). 
12) Oki T., Toma-Okura A., Yamada S., J. Pharmcol. Exp. Ther, 316, 1137-1145 (2006).

13) Oki T., Kawashima A., Uchida M., Yamada S., Life Sci., 76, 24452456 (2005).

14) Tashiro M., Mochizuki H., Sakurada Y., Ishii K., Oda K., Kimura Y., Sasaki T., Ishiwata K., Yanai K., Br. J. Clin. Pharmacol., 61, 16-26 (2006).

15) Kessler R. M., Ansari M. S., Riccardi P., Li R., Jayathilake K., Dawant B., Meltzer H. Y., Neuropsychopharmacology, 30, 2283-2289 (2005).

16) Matsui-Sakata A., Ohtani H., Sawada Y., Drug Metab. Pharmacokinet., 20, 368-378 (2005).

17) Yamada Y., Ito K., Nakamura K., Sawada Y., Iga T., Biol. Pharm. Bull., 16, 1251-1259 (1993).

18) Matsui-Sakata A., Ohtani H., Sawada Y., Drug Metab. Pharmacokinet., 20, 187-199 (2005).

19) Lee C.-M., Farde L., Trends Pharmacol. Sci., 27, 310-316 (2006).
20) Shibukawa A., Ishizawa N., Kimura T., Sakamoto Y., Ogita K., Matsuo Y., Kuroda Y., Matayatsuk C., Nakagawa T., Wainer I. W., J. Chromatogr. B, 768, 177-178 (2002).

21) Shibukawa A., Yoshikawa Y., Kimura T., Kuroda Y., Nakagawa T., Wainer I. W., J. Chromatogr. B, 768, 189-197 (2002).

22) Arunlakshana O., Schild H. O., Br. J. Pharmacol., 124, 883-888 (1959).

23) Arima Y., Kubo C., Tsujimoto M. Ohtani H., Sawada Y., Ann. Pharmacother, 39, 567-571 (2005).

24) Zobrist R. H., Quan D., Thomas H. M., Stanworth S., Sanders S. W., Pharm. Res., 20, 103-109 (2003)

25) Angelico P., Velasco C., Guarneri L., Sironi G., Leonardi A., Testa R., BMC Pharmacol., 5, 14 (2005).

26) Ehlert F. J., Life Sci., 74, 355-366 (2003).

27) Ireland-Denny L., Parihar A. S., Miller T. R., Kang C. H., Lrueger K. M., Esbenshade T. A., Hancock A. A., Eur. J. Pharmacol., 433, 141150 (2005). 